\title{
Trainee fatigue: Are new limits on work hours enough?
}

\author{
Steven K. Howard, David M. Gaba
}

ß See related article page 965

I $\mathrm{t}$ should come as no surprise that working in a busy hospital environment for 60 to 80 hours each week engenders a significant amount of sleep deprivation, with all of the attendant physiologic consequences. Sleep deprivation of the magnitude experienced by medical trainees has been shown to impair performance, worsen mood and compromise patient and provider safety. ${ }^{1}$ In North America, new guidelines and requirements should eliminate the egregious 100- to 120-hour workweek that used to be all too common for residents. Despite this, clinicians, academicians and training-program coordinators are still grasping for the right balance of safety, education and service in residents' workloads. Established methods of residency training may have to be altered substantially to accommodate the reduction of work hours.

Resident well-being, patient safety and the anticipation of government regulations have all been cited as motivation for limiting residents' work hours. The agreement set forth in July 2000 by the Professional Association of Internes and Residents of Ontario and the Ontario Council of Teaching Hospitals limits the number of call periods required of residents. ${ }^{2}$ Similarly, in July 2003 the Accreditation Council for Graduate Medical Education in the United States instituted common program requirements that limit work hours and call periods for all residency programs. ${ }^{3}$ These imposed limits still allow for very long work hours that are outside the limits imposed by other hazardous industries. ${ }^{4}$ In fact, it is now commonplace in the transportation industry for investigations to evaluate the work and sleep schedules of those involved in a crash. ${ }^{5}$ If we were to impose such investigative techniques to error analysis in health care, fatigue would certainly be cited as a contributing factor in many adverse events.

Many studies on the effects of fatigue and long work hours on medical trainees have been published over the past 25 years. Most have attempted to focus on the performance of subjects in both a fatigued and rested state, testing the hypothesis that performance will be worse in a condition of greater fatigue. However, many of these studies have failed to define fatigue rigorously and have not included the cumulative effects of weeks and months of sleep deprivation. This can mean that some studies actually compare groups that have similar levels of cumulative fatigue. ${ }^{6}$ The physical stress of sleep deprivation and fatigue has been studied in other populations, but has been largely absent from the literature evaluating the effects of fatigue on clinicians. ${ }^{?}$

In this issue (page 965), Parshuram and colleagues describe a small prospective study of critical care fellows who were working under the Ontario guidelines that limit call periods, on average, to every fourth night. ${ }^{8}$ Beyond the largely expected results (long shifts, little sleep, many interruptions), some new and important physiologic information has been revealed that opens the door for larger studies. In a subset of fellows studied with continuous Holter monitoring, heart rate variability showed dominance of the sympathetic nervous system. This physiologic alteration might have been due to the inherent stress of being on call, or to the increased physical activity of the subjects, who walked an average of $6.3 \mathrm{~km}$ during their shift. The authors also noted that some fellows neglected their own basic needs, as their urine specific gravity and ketone levels indicated that they were dehydrated.

Their study suggests that a potential strategy to mitigate some of the effects of fatigue would be to add another physician to the call team, thus distributing the workload among more people. The cost of such a strategy, which would likely be quite substantial, is not addressed.

Although the number of subjects was small, Parshuram and colleagues' work provides further evidence that, even when it is compliant with "new and improved" requirements, clinical work alters normal physiology. The authors should be congratulated: field studies of this type are difficult to perform on busy clinicians but are an important adjunct to laboratory-based investigations. Although this study extends existing research, larger studies are still required to better elucidate the effects of our work environment on practitioner physiology and performance and on the safety of both practitioners and patients. In this way we will be better able to monitor the changes that will be promulgated within health care circles, whether adopted voluntarily or imposed externally through regulation or legislation, and to determine whether they are sufficient to improve performance and enhance safety.

Drs. Howard and Gaba are with the Patient Safety Center of Inquiry, VA Palo Alto Health Care System and Stanford University School of Medicine, Palo Alto, Calif.

Competing interests: None declared.

Contributors: Drs. Howard and Gaba contributed equally to the conception and ideas presented in this article. Dr. Howard drafted and Dr. Gaba revised the article. Both authors approved the final version. 


\section{References}

1. Mitler MM, Dement WC, Dinges DF. Sleep medicine, public policy, and public health. In: Kryger MH, Roth T, Dement WC, editors. Principles and practice of sleep medicine. 3rd ed. Philadelphia: WB Saunders; 2000. p. 580-8.

2. Professional Association of Internes and Residents of Ontario. New call provisions enforceable January 1, 2001. Available: www.pairo.org/about /callschedulingrules.html (accessed 2004 Jan 5).

3. Accreditation Council for Graduate Medical Education. ACGME duty hours standards now in effect for all residency programs. Available: www.acgme.org /Media/news7_1_03.asp (accessed 2004 Jan 5).

4. Gaba DM, Howard SK. Fatigue among clinicians and the safety of patients N Engl 7 Med 2002;347:1249-55.

5. Rosekind MR, Gregory KB, Miller DL, Co EL, Lebacqz JV. Aircraft accident report: uncontrolled collision with terrain, American International Airways Flight 808, Douglas DC-8, N814CK, U.S. Naval Air Station, Guan- tanamo Bay, Cuba, August 18, 1993. [Report no. NTSB/AAR-94/04]. Washington, DC: National Transportation Safety Board; 1994.

6. Howard SK, Gaba DM, Rosekind MR, Zarcone VP. The risks and implications of excessive daytime sleepiness in resident physicians. Acad Med 2002;77:1019-25.

7. Franzini C. Cardiovascular physiology: the peripheral circulation. In: Kryger MH, Roth T, Dement WC, editors. Principles and practice of sleep medicine. 3rd ed. Philadelphia: WB Saunders; 2000. p. 193-203.

8. Parshuram CS, Dhanani S, Kirsh JA, Cox PN. Fellowship training, workload, fatigue and physical stress: a prospective observational study. CMA7 2004;170(6): $965-70$.

Correspondence to: Dr. David M. Gaba, VA Palo Alto Health

Care System, Anesthesia Service, 112A-3801 Miranda Ave.,

Palo Alto CA 94304; fax 650 852-3423; gaba@stanford.edu

\title{
Interventions to promote breast-feeding: applying the evidence in clinical practice
}

\author{
Valerie A. Palda, Jeanne-Marie Guise, C. Nadine Wathen, with the Canadian Task Force \\ on Preventive Health Care
}

I $\mathrm{n}$ this document, the Canadian Task Force on Preventive Health Care (CTFPHC) updates its earlier breastfeeding recommendations ${ }^{1}$ by presenting evidence on interventions that improve the initiation or duration of breast-feeding (or both). Breast-feeding has been shown in both developing and developed countries to improve the health of infants and their mothers, making it the optimal method of infant nutrition. ${ }^{2,3}$ Although the prevalence of breast-feeding in Canada has risen, with over three-quarters of mothers now initiating breast-feeding, the duration of this practice remains short of the recommended World Health Organization (WHO) targets of exclusive breastfeeding for 6 months and partial breast-feeding for up to 2 years. ${ }^{4,5}$ Recent Canadian data indicate that $22 \%$ of recent mothers aged 15-49 years breast-feed for less than 3 months, and $35 \%$ do so for at least 3 months. ${ }^{6}$ This premature discontinuation is more a result of difficulty with breast-feeding, including lack of information and support, than of women's choice. ${ }^{7}$ In fact, the number of Canadian hospitals that would qualify as "baby-friendly" according to WHO-UNICEF criteria ${ }^{8}$ was 5 of 523 hospitals responding to a 1993 survey, ${ }^{9}$ and according to UNICEF only a single hospital had that designation in 2002. ${ }^{10}$

In a joint endeavour, the CTFPHC and the US Preventive Services Task Force systematically reviewed the randomized trial evidence for the effectiveness of all counselling interventions originating in a clinician's practice (such as antepartum and postpartum support groups, education, telephone support or peer counsellors) to increase the rate of initiation or the duration of breast-feeding. ${ }^{11,12}$ We present here the new CTFPHC recommendations, based on the joint systematic review as well as a key Canadian trial ${ }^{13}$ published after that review and tailored to the Canadian health care setting (Table 1). Definitions of the levels of evidence and grades of recommendations used in Table 1 are available in an online appendix to this article (www.cmaj.ca/cgi/content/full/170/6/976/DC1).

Interventions consisting of antepartum structured breast-feeding education are effective at improving both initiation and continuation of breast-feeding during the first 2 months postpartum, compared with usual care. ${ }^{14-28}$ These interventions, consisting of individual or group instruction about breast-feeding knowledge, practical skills and problem-solving techniques, were effective when provided by lactation specialists or nurses, and both single sessions and multiple sessions were effective. Postpartum telephone or in-person support by lactation specialists, nurses or peer counsellors enhanced the effectiveness of these interventions. In addition, the use of peer counsellors improved breast-feeding rates and duration, and these types of programs may represent a cost-effective alternative to professionally delivered services, especially in locations or settings where professional services are scarce or not available. ${ }^{13,20,29-32}$ The CTFPHC recommends against the use of written materials (which have not been shown to be effective when used alone, , $^{16,22,26,33-36}$ although no harm was demonstrated) and commercial discharge packages (which have been shown to decrease breast-feeding rates). ${ }^{37}$ Unfortunately, advice from a woman's primary clinician (such as family physician, obstetrician or midwife) has not been sufficiently evaluated, and a research gap remains in this area.

The recommendations presented here (Table 1) do not 